\title{
International Journal

\section{Adsorption Mechanisms and Transport Behavior between Selenate and Selenite on Different Sorbents}

Michelle MV Snyder ${ }^{1}$ and Wooyong Um ${ }^{1,2^{*}}$

${ }^{1}$ Energy and Environment Directorate, Pacific Northwest National Laboratory, Richland, WA 99354, USA

2Division of Advanced Nuclear Engineering, Pohang University of Science and Technology (POSTECH), Pohang, South Korea (ROK)

"Corresponding author: Wooyong Um, Energy and Environment Directorate, Pacific Northwest National Laboratory, Richland, WA 99354, USA, Tel: 509-372-6227; Fax: 509- 371-7249; E-mail: wooyong.um@pnnl.gov

Received date: March 12, 2014; Accepted date: April 22, 2014; Published date : April 30, 2014

Copyright: $\odot 2014$ Um W, et al. This is an open-access article distributed under the terms of the Creative Commons Attribution License, which permits unrestricted use, distribution, and reproduction in any medium, provided the original author and source are credited.

\begin{abstract}
Adsorption of different oxidation species of selenium (Se), selenate $\left(\mathrm{SeO}_{4}{ }^{2-}\right)$ and selenite $\left(\mathrm{SeO}_{3}{ }^{2-}\right)$, with varying pHs (2-10) and ionic strengths $\left(\mathrm{I}=0.01 \mathrm{M}, 0.1 \mathrm{M}\right.$ and $\left.1.0 \mathrm{M} \mathrm{NaNO}_{3}\right)$ was measured on quartz, aluminum oxide, and synthetic iron oxide (ferrihydrite) using batch reactors to obtain a more detailed understanding of the adsorption mechanisms (e.g., inner- and outer-sphere complex). In addition to the batch experiments with single minerals contained in native Hanford Site sediment, additional batch adsorption studies were conducted with native Hanford Site sediment and groundwater as a function of 1) total Se concentration (from 0.01 to $10 \mathrm{mg} \mathrm{L}^{-1}$ ) and 2) soil to solution ratios (1:20 and 1:2 grams per $\mathrm{mL}$ ). Results from these batch studies were compared to a set of saturated column experiments that were conducted with natural Hanford sediment and groundwater spiked with either selenite or selenate to observe the transport behavior of these species. Both batch and column results indicated that selenite adsorption was consistently higher than that of selenate in all experimental conditions used. These different adsorption mechanisms between selenite and selenate result in the varying mobility of $\mathrm{Se}$ in the subsurface environment and explain the dependence on the oxidation species.
\end{abstract}

Keywords: Selenite; Selenate; Inner-sphere complex; Outer-sphere complex; Adsorption

\section{Introduction}

Selenium (Se) is required for adequate nutrition, but at high concentrations Se can be toxic to humans and animals. In humans, exposure to high concentrations of Se can result in loss of hair and fingernails, cause numbness in the fingers or toes, and weaken the body's nervous and circulatory systems [1]. Similar to humans, animals also have a narrow range between deficient and toxic concentrations of Se. Contamination of Se, caused by irrigation drainage, was discovered in 1983 at Kesterson Reservoir in California and was linked to deformities in waterfowl [2]. Because of the environmental and human health risks associated with Se, the U.S. Environmental Protection Agency (EPA) has determined the Maximum Contaminant Level (MCL) for Se in drinking water to be 0.05 parts per million (ppm) [1]. The MCL for Se is sometimes exceeded in areas that have a large amount of mining, industrial activity, and seleniferous soils $[1,3]$. Furthermore, the planned disposal of immobilized low-activity waste (ILAW) glass containing ${ }^{79} \mathrm{Se}$ $\left(\mathrm{t}_{1 / 2}=2.9 \times 10^{5}\right.$ years) [4], located in the 200 East area of the Hanford Site, southeastern Washington State, may also pose a significant risk for radioactive Se release [5]. Dissolution of the vitrified radioactive waste matrix containing ${ }^{79} \mathrm{Se}$, a fission product of ${ }^{235} \mathrm{U}$, could result in Se release into the environment. Depending on the rate of glass dissolution, Se that is released from the host matrix can be transported through the vadose zone and can contaminate the underlying sediment and groundwater aquifer. To prevent spreading of radioactive Se contamination, a more in depth understanding of the migration of Se in the environment is required [5-7].
The ability to predict the fate and transport of toxic and radioactive Se in subsurface environments requires an understanding of the sorption processes that occur at the mineral-water interface. The effect of sorption on contaminant mobility is determined by molecular level processes involving the sorption complex, which can be divided into three distinct mechanisms: 1) adsorption (inner-sphere vs. outersphere complex), 2) absorption, and 3) surface precipitation $[8,9]$. Although each individual process is extremely important, adsorption is expected to play the largest role in the mobility of most contaminants, including Se.

The process of adsorption occurs when adsorbate accumulates on the surface of a solid (adsorbent) at the solid-water interface, where the ions, liquid, or gas molecules are held onto the surface without the development of a three-dimensional molecular arrangement [9]. Adsorption not only influences the distribution of contaminants between the aqueous phase and particulate matter, but it also affects the electrostatic properties of particles and the reactivity of mineral surfaces [10].

Oxyanions selenite $\left(\mathrm{SeO}_{3}{ }^{2-}\right)$ and selenate $\left(\mathrm{SeO}_{4}{ }^{2-}\right)$ are dominant in both mild and strong oxidizing conditions and are the most mobile aqueous species of Se [11]. Numerous studies have been conducted to evaluate the adsorption behavior of these oxidation species, $\mathrm{SeO}_{3}{ }^{2-}$ and $\mathrm{SeO}_{4}{ }^{2}$ [12-15]. Many of these studies focused on the effects of various environmental factors on $\mathrm{SeO}_{3}{ }^{2-}$ and $\mathrm{SeO}_{4}{ }^{2-}$ adsorption. For example, Balistrieri and Chao studied the effects of $\mathrm{pH}$, temperature, total Se concentrations, and competing anions on the adsorption of $\mathrm{SeO}_{3}{ }^{2-}$ on goethite $(\mathrm{FeOOH})[12]$. Results demonstrated that $\mathrm{SeO}_{3}{ }^{2-}$ adsorption increased with decreasing $\mathrm{pH}$ and an increase in the solid to solution ratio. However, adsorption of $\mathrm{SeO}_{3}{ }^{2-}$ decreased with an increase in the total Se concentration and in the presence of competing anions Ffisuch as phosphate, silicate or citrate which bind strongly to the 
Page 2 of 8

goethite surface. Zhang and Sparks conducted studies to determine the mechanisms of $\mathrm{SeO}_{3}{ }^{2-}$ and $\mathrm{SeO}_{4}{ }^{2-}$ at the goethite/water interface [16]. Their results suggested that $\mathrm{SeO}_{3}{ }^{2-}$ forms a stronger inner-sphere surface complex whereas $\mathrm{SeO}_{4}{ }^{2-}$ forms a weaker bonded outer-sphere surface complex. Gonzalez et al. [17] studied an iron/manganese oxide nanomaterial as a potential material for the treatment technology and removal of $\mathrm{SeO}_{3}{ }^{2-}$ and $\mathrm{SeO}_{4}{ }^{2-}$. Results found sorption on the nanomaterial to be $\mathrm{pH}$ independent (between $\mathrm{pH} 2$ to 6 ) and sorption of both oxyanions to be effected by the presence of phosphate with a larger decrease in $\mathrm{SeO}_{4}{ }^{2-}$ sorption than $\mathrm{SeO}_{3}{ }^{2-}$. The addition of sulfate only effected the sorption of $\mathrm{SeO}_{4}{ }^{2-}$ and the addition of nitrate and chloride had no effect on the sorption of either $\mathrm{SeO}_{3}{ }^{2-}$ or $\mathrm{SeO}_{4}{ }^{2-}$. Additional studies conducted to determine sorption onto simple mineral systems include Zonkhoeva [18] that studied the sorption of $\mathrm{SeO}_{3}{ }^{2-}$ on natural zeolites and Yoon, et al. [19] which studied sorption of $\mathrm{SeO}_{4}{ }^{2-}$ onto zero-valent iron. In general, studies that compared adsorption of $\mathrm{SeO}_{3}{ }^{2-}$ and $\mathrm{SeO}_{4}{ }^{2-}$ consistently found that $\mathrm{SeO}_{3}{ }^{2-}$ is more rapidly adsorbed than $\mathrm{SeO}_{4}{ }^{2-}$ and lower $\mathrm{pH}$ conditions favor stronger Se adsorption [20].

Although the information discussed above represents a majority of the research on the adsorption of $\mathrm{SeO}_{3}{ }^{2-}$ and $\mathrm{SeO}_{4}{ }^{2-}$, few studies are available on the transport of these oxyanions under real environmental conditions. Therefore, the purpose of this study was to evaluate how changes in the Se redox state $\left(\mathrm{SeO}_{3}{ }^{2-}\right.$ or $\left.\mathrm{SeO}_{4}{ }^{2-}\right)$ will affect adsorption and transport of Se in native Hanford Site soil and groundwater conditions. Hanford Site groundwater contains several of the anions expected to compete with Se for available adsorption sites. To evaluate the adsorption and transport behavior of $\mathrm{SeO}_{3}{ }^{2-}$ or $\mathrm{SeO}_{4}{ }^{2-}$, a set of batch adsorption and saturated column experiments were conducted with Hanford sediment and groundwater spiked with either $\mathrm{SeO}_{3}{ }^{2-}$ or $\mathrm{SeO}_{4}{ }^{2-}$. In addition to these experiments, a set of batch adsorption experiments using pure single minerals [e.g., quartz $\left(\mathrm{SiO}_{2}\right)$, aluminum oxide $\left(\mathrm{Al}_{2} \mathrm{O}_{3}\right)$, and iron oxide (2-line ferrihydrite, $\left(\mathrm{Fe}(\mathrm{OH})_{3}\right)$ ] contained in native Hanford sediments were also conducted as a function of ionic strength and $\mathrm{pH}$. The two principal objectives of these experiments were 1) to determine the mineral phase that has the largest effect on Se adsorption and 2) to use macroscopic methods to determine whether or not $\mathrm{SeO}_{3}{ }^{2-}$ and $\mathrm{SeO}_{4}{ }^{2-}$ form an inner- or outersphere complex on the mineral surface. These and other results obtained from this study will improve our understanding of the release and transport of Se from the radioactive waste glass that will be buried in the Integrated Disposal Facility (IDF) on the Hanford Site.

\section{Materials and Methods}

\section{Hanford sediment characterization}

Hanford sediment was utilized as an adsorbent to determine the adsorption of $\mathrm{SeO}_{3} 2$ - and $\mathrm{SeO}_{4}{ }^{2-}$. The sediment was collected from borehole C3177 (299-E24-21) located in the center of the 200 East Area, northeast corner of the ILAW disposal site, at the Hanford Site Nuclear Reservation located in southeastern Washington state [21]. The sediment, C3177-110, was obtained from borehole C3177 by homogenizing four two-foot long $(71.0 \mathrm{~cm})$ cores to provide sufficient volume of representative Hanford sediment.

The Hanford formation ${ }^{1}$ can be subdivided into three main layers within the ILAW disposal facility and consists of pebble to bouldersized gravel and fine to coarse grained sand with interbedded, thin silt and/or clay beds [22]. Composite C3177-110 is representative of Hanford formation layer II and is dominated by sand. Particle size distribution was determined by wet sieve and hydrometer methods, and revealed that the sediment is comprised of gravel (3.85 $\mathrm{wt} \%)$, sand (88.6 wt\%), silt (6.19 wt\%), and clay (1.36 wt\%) [21]. X-ray diffraction (XRD) analysis revealed that the Hanford sediment is dominated by quartz and feldspars with lesser amounts of chlorite, mica and amphibole, which is typical of Hanford Site sediments (Table 1). Additional sediment characterization included moisture content, carbon content, BET surface area, bulk sediment composition determined by $\mathrm{x}$-ray fluorescence (XRF), and mineralogical content of clay determined by X-ray diffraction (XRD). These results are summarized in Tables 1 and 2.

\begin{tabular}{|c|c|c|c|c|c|c|c|c|c|c|}
\hline \multicolumn{6}{|c|}{$\begin{array}{l}\text { Mineral phase on bulk sample } \\
(\mathrm{wt} \%)^{1}\end{array}$} & \multirow{2}{*}{ 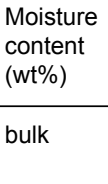 } & \multicolumn{2}{|c|}{$\begin{array}{l}\text { Surface area } \\
\left(\mathrm{m}^{2} / \mathrm{g}\right)\end{array}$} & \multicolumn{2}{|c|}{$\begin{array}{l}\text { Carbon content (wt } \\
\%)^{2}\end{array}$} \\
\hline Q & A & $P$ & $\mathrm{~K}$ & M & C & & clay & total & $\begin{array}{l}\text { inorgan } \\
\text { ic }\end{array}$ & \\
\hline 45 & 1 & 25 & 19 & 9 & 2 & 2.76 & 5.11 & 41.8 & 0.20 & 0.19 \\
\hline
\end{tabular}

Table 1: Characterization of the composite sediment including moisture content, carbon content and mineralogy of bulk sample by XRD (modified from [21]). 1) Mineral phase indicates Q (quartz), A (Amphibole), P (Plagioclase), K (K-feldspar), M (Mica), and C (Chlorite). 2) Organic carbon content is determined by difference between total and inorganic carbon contents.

\begin{tabular}{|l|l|l|l|l|l|l|l|l|l|l|l|l|l|}
\hline \multicolumn{1}{|l|}{ Mineral phase of clay $(\boldsymbol{w t} \%)$} & \multicolumn{6}{l|}{ Bulk composition of major element oxides $(\boldsymbol{w t} \%)$} \\
\hline Smectite & IIlite & Chlorite & Kaolinite & $\mathrm{SiO}_{2}$ & $\mathrm{Al}_{2} \mathrm{O}_{3}$ & $\mathrm{TiO}_{2}$ & $\mathrm{Fe}_{2} \mathrm{O}_{3}$ & $\mathrm{MnO}$ & $\mathrm{CaO}$ & $\mathrm{MgO}$ & $\mathrm{K}_{2} \mathrm{O}$ & $\mathrm{Na}_{2} \mathrm{O}$ & $\mathrm{P}_{2} \mathrm{O}_{5}$ \\
\hline 26 & 51 & 16 & 7 & 70.4 & 13.2 & 0.672 & 4.91 & 0.077 & 3.72 & 1.87 & 2.54 & 2.87 & 0.153 \\
\hline
\end{tabular}

Table 2: Characterization of the composite sample including clay mineralogy by XRD and major elemental composition by XRF (modified from [21]).

\section{Preparation and characterization of pure single minerals}

White quartz sand $\left(\mathrm{SiO}_{2}\right)$, 50-70 mesh size (Aldrich Chemical Company) was acid treated (to remove any impurities) with analytical grade concentrated sulfuric acid $\left(\mathrm{H}_{2} \mathrm{SO}_{4}\right)$ for two days, rinsed several times with double deionized (DDI) water, and oven dried at $85^{\circ} \mathrm{C}$ for 48 hours prior to use. The cleaning of quartz was based on a procedure used by [23].

1 The term "Hanford formation" is used informally to describe Pleistocene cataclysmic flood deposits within the Pasco Basin. It is not a formalized stratigraphic unit. 
Page 3 of 8

Synthetic aluminum oxide $\left(\mathrm{Al}_{2} \mathrm{O}_{3}\right)$, or transition Alumina (C-33), is a porous and high-surface area synthetic aluminum oxide with a specific surface area of $110 \mathrm{~m}^{2} \mathrm{~g}^{-1}$ [24]. The alumina (C-33) used in this study was created by the partial dehydration of aluminum hydroxides and oxyhydroxides, where the final product is a completely dehydrated oxide (corundum) [25]. Additional characterization of this aluminum oxide can be found in reference [25].

The synthetic iron oxide [ferrihydrite, $\mathrm{Fe}(\mathrm{OH})_{3}$ ] preparation was based on Schwertmann and Cornell [26]. The ferrihydrite was prepared by neutralizing $0.2 \mathrm{M}$ ferric nitrate $\left[\mathrm{Fe}\left(\mathrm{NO}_{3}\right)_{3} \cdot 9 \mathrm{H}_{2} \mathrm{O}\right]$, from Aldrich Chemical Company; (analytical grade) with $1.0 \mathrm{M}$ sodium hydroxide $(\mathrm{NaOH})$, from J.T. Baker; (analytical grade). The resulting solid was washed by successive centrifuging and decanting with double deionized water (DDI). The solid was filtered from solution by vacuum using a $0.45 \mu \mathrm{m}$ filter unit. Powder X-ray diffraction (XRD) patterns were obtained using a Scintag, Pad-V X-Ray Diffractometer (XRD) with a $\mathrm{Cu}$ source. The ferrihydrite was analyzed on the XRD using a 2-Theta range from $2^{\circ}$ to $65^{\circ}$, a step size of $0.01^{\circ}$, and a 2 second count time at each step. The XRD pattern was identified as ferrihydrite (Figure 1) using the JADE software (MDI, Livermore, California).

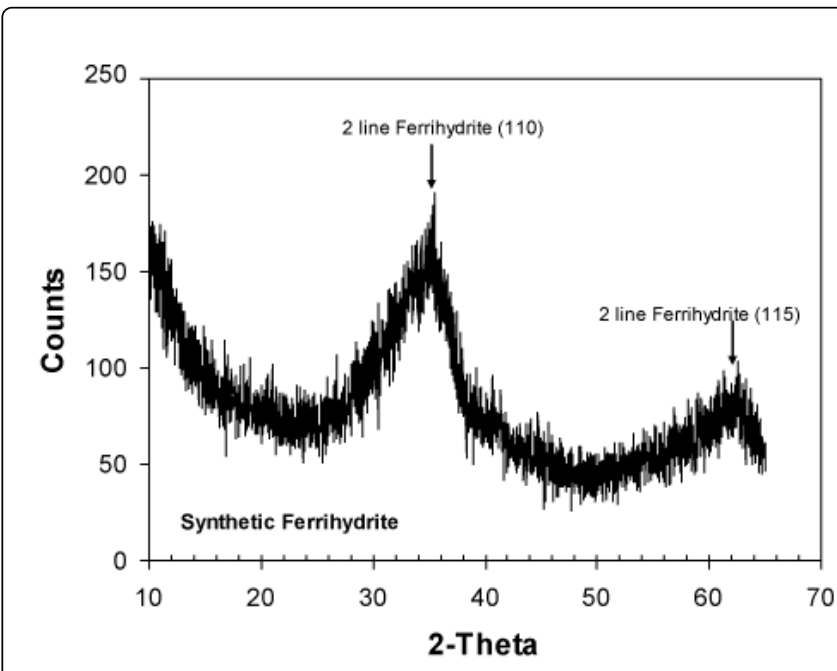

Figure 1: XRD pattern for the synthetic ferrihydrite.

\section{Batch adsorption experiments}

Groundwater used for the adsorption and column experiments with Hanford sediment was collected from the well 699-49-100C located in the 600 area of the Hanford Site. Well $699-49-100 \mathrm{C}$ is an uncontaminated background monitoring well. Analyses of cations and anions in this groundwater were conducted using an inductively coupled plasma-optical emission spectroscopy (ICP-OES) and an Ion Chromatograph (IC), respectively. The $\mathrm{pH}$ was measured with a solidstate $\mathrm{pH}$ electrode and a $\mathrm{pH}$ meter calibrated with buffers 7 and 10 . The electrical conductivity (EC) was measured using a Pharmacia Biotech Conductivity Monitor. Approximately 2 to 3 milliliters of filtered sample were measured in the conductivity meter and compared to potassium chloride standards with a range of 0.001 to 1.0 $\mathrm{M}$. Chemical compositions as well as the $\mathrm{pH}$ and $\mathrm{EC}$ values for this groundwater are shown in Table 3.

\begin{tabular}{|l|l|l|l|}
\hline $\begin{array}{l}\text { Elements } \\
\text { (cations) }\end{array}$ & $\begin{array}{l}\text { Concentration } \\
\text { (mg/L) }\end{array}$ & $\begin{array}{l}\text { Elements } \\
\text { (anions) }\end{array}$ & $\begin{array}{l}\text { Concentration } \\
\text { (mg/L) }\end{array}$ \\
\hline $\mathrm{Ca}$ & 59.5 & $\mathrm{HCO}_{3}$ & 169 \\
\hline $\mathrm{Si}$ & 28 & $\mathrm{SO}_{4}$ & 70.6 \\
\hline $\mathrm{S}$ & 26.1 & $\mathrm{Cl}$ & 18.9 \\
\hline $\mathrm{Na}$ & 24.4 & $\mathrm{NO}_{3}$ & 9.44 \\
\hline $\mathrm{Mg}$ & 22 & $\mathrm{~F}$ & 0.45 \\
\hline $\mathrm{K}$ & 7.5 & & \\
\hline $\mathrm{Sr}$ & 0.236 & & \\
\hline $\mathrm{Zn}$ & 0.283 & & \\
\hline $\mathrm{Cr}$ & 0.002 & & \\
\hline $\mathrm{Mo}$ & 0.002 & & \\
\hline $\mathrm{pH}$ (measured) & $=8.04 ;$ electrical conductivity=0.474 mS/cm \\
\hline
\end{tabular}

Table 3: Chemical composition, $\mathrm{pH}$, and conductivity of groundwater (699-49-100C).

Batch adsorption experiments were conducted in duplicate for adsorption of $\mathrm{SeO}_{3}{ }^{2-}$ and $\mathrm{SeO}_{4}{ }^{2-}$ on the $\mathrm{C} 3177$ sediment. Particles greater than $2 \mathrm{~mm}$ were removed prior to using the sediment and the sediment was pre-equilibrated with the Hanford groundwater. The groundwater was added to the sediments, the sediments were shaken overnight, centrifuged, and the $\mathrm{pH}$ measured and then the supernatant was decanted. This was repeated three times until the $\mathrm{pH}$ of the supernatant groundwater did not change after contact overnight with the sediment. Pre-equilibration was done to ensure that reactions that occurred during laboratory batch sorption experiments were not due to any other reactions (e.g. dissolution) except adsorption. Batch experiments were conducted in $15 \mathrm{~mL}$ polypropylene centrifuge tubes with solid to solution ratio of 1:20 or 1:2 (gram per $\mathrm{mL}$ ). Initial concentrations (Co) of $\mathrm{SeO}_{3}{ }^{2-}$ and $\mathrm{SeO}_{4}{ }^{2-}$ ranged from 0.01 to $10 \mathrm{mg}$ $\mathrm{L}^{-1}$ and were prepared by the addition of $\mathrm{Na}_{2} \mathrm{SeO}_{3}$ or $\mathrm{Na}_{2} \mathrm{SeO}_{4}$, respectively, to the groundwater.

Additional batch adsorption experiments were conducted for $\mathrm{SeO}_{3}{ }^{2-}$ and $\mathrm{SeO}_{4}{ }^{2-}$ on single minerals such as quartz, aluminum and iron oxide under varying ionic strength $\left(\mathrm{I}=0.01\right.$ to $\left.1.0 \mathrm{M} \mathrm{NaNO}_{3}\right)$ and $\mathrm{pH}$ (2 to 10) conditions. Experiments were conducted at a solid to solution ratio of 1:100 (gram per $\mathrm{mL}$ ) with the addition of $1 \mathrm{mg} \mathrm{L}^{-1}$ of $\mathrm{Na}_{2} \mathrm{SeO}_{3}$ or $\mathrm{Na}_{2} \mathrm{SeO}_{4}$, respectively, in $\mathrm{NaNO} 3$ solution. The $\mathrm{pH}$ was adjusted by the addition of $0.01 \mathrm{M}$ nitric acid $\left(\mathrm{HNO}_{3}\right)$ or $0.01 \mathrm{M}$ sodium hydroxide $(\mathrm{NaOH})$.

Hanford sediment or pure single minerals were contacted with solution spiked with $\mathrm{SeO}_{3}{ }^{2-}$ or $\mathrm{SeO}_{4}{ }^{2-}$. After shaking for 7 days on a slowly moving platform shaker, the slurry sediment sample was centrifuged to separate the solids out of solution. The final $\mathrm{pH}$ was measured, and the supernatant was decanted and filtered through a $0.45 \mu \mathrm{m}$ syringe filter. Solution was analyzed for Se concentration using an inductively coupled plasma mass spectrometer (ICP-MS). The difference in $\mathrm{C}_{\mathrm{o}}$ and the final concentration of $\mathrm{SeO}_{3}{ }^{2-}$ or $\mathrm{SeO}_{4}{ }^{2-}$ in solution was used for adsorption of Se onto the sediments.

In addition, two different types of experimental control samples were also prepared to determine 1) whether or not $\mathrm{SeO}_{3}{ }^{2-}$ and $\mathrm{SeO}_{4}{ }^{2-}$ 
Page 4 of 8

adsorbed onto the walls of the test vessels and 2) to determine the contribution of natural $\mathrm{SeO} 32-$ and $\mathrm{SeO}_{4}{ }^{2-}$ released from the unreacted Hanford sediment. The final solution was also analyzed for Se concentrations, and showed negligible Se adsorption onto the test tube walls and no natural Se release from the sediment.

\section{Calculation of partition coefficient $(\mathrm{Kd})$}

The partition coefficient $\left(\mathrm{K}_{\mathrm{d}}\right)$ is a measure of adsorption and is defined as the ratio of the amount of an adsorbate sorbed on a solid to the amount of adsorbate still in solution at equilibrium [27]. The expression is as follows:

$$
K_{d}=\frac{A_{i}}{C_{i}}
$$

where $A_{i}=$ adsorbate on the solid at equilibrium ( $\mu \mathrm{g} \mathrm{g}^{-1}$ ); $\mathrm{C}_{\mathrm{i}}=$ adsorbate remaining in solution at equilibrium $\left(\mu \mathrm{g} \mathrm{ml}^{-1}\right)$. For the batch studies conducted during this experiment, the $K_{d}$ values were calculated using the following equation:

$$
K_{d}=\frac{V_{W}\left(C_{o}-C_{i}\right)}{M_{\text {sed }} C_{i}}
$$

where $\mathrm{V}_{\mathrm{w}}=$ known volume of solution $(\mathrm{ml}) ; \mathrm{C}_{\mathrm{o}}=$ initial concentration of adsorbate $\left(\mu \mathrm{g} \mathrm{mL}^{-1}\right) ; \mathrm{M}_{\text {sed }}=$ known mass of sediment $(\mu \mathrm{g})$.

\section{Column experiments and determination of retardation factor $\left(\mathbf{R}_{\mathbf{f}}\right)$}

Two borosilicate glass columns (Kontes Chromaflex Chromatography columns, $\mathrm{L}=10 \mathrm{~cm}$, diameter $=2.5 \mathrm{~cm}$ ) were uniformly packed with sediment C3177-110 after removing gravel ( $>2$ $\mathrm{mm}$ size fraction). Two individual columns were utilized to evaluate the mobility of $\mathrm{SeO}_{3}{ }^{2-}$ and $\mathrm{SeO}_{4}{ }^{2-}$, respectively. An AVI Micro $210 \mathrm{~A}$ Infusion Pump was used to control the constant flow rate. The columns were initially saturated with groundwater at a pumping rate $\left(10 \mathrm{~mL}\right.$ hour $\left.^{-1}\right)$ faster than what was used during the experiment to remove any dispersible particles and to make sure that a steady flow was maintained. Prior to conducting the Se transport experiment, the flow rate was decreased to $0.5 \mathrm{ml}$ hour $^{-1}$ until a steady flow rate was maintained. This flow rate was chosen to allow the $\mathrm{SeO}_{3}{ }^{2-}$ and $\mathrm{SeO}_{4}{ }^{2-}$ to remain in contact with sediment in the column for approximately one day. Prior to introducing Se, a bromide $(\mathrm{Br})$ was added to the groundwater and introduced as a nonreactive tracer (no adsorption to the sediment) in each column to provide a comparison of Br mobility to the $\mathrm{SeO}_{3}{ }^{2-}$ and $\mathrm{SeO}_{4}{ }^{2-}$ transport results as well as hydrodynamic dispersion of the flow. Once completion of $\mathrm{Br}$ breakthrough in the column was attained, approximately $7 \mathrm{mg} \mathrm{L}^{-1}$ of $\mathrm{SeO}_{3}{ }^{2-}$ or $\mathrm{SeO}_{4}{ }^{2-}$, respectively, spiked in groundwater was introduced to each column. The Se was pumped through the columns for approximately 13 pore volumes and the amount of Se in the effluent was measured using an inductively coupled plasma optical emission spectrometer (ICP-OES). Transport parameters were determined by curve fitting (based on the advection-dispersion equation) to the measured breakthrough curves (BTCs) using the CXTFIT code $[28,29]$. Breakthrough curves (BTCs) were graphically represented by plotting the relative concentration, $\mathrm{C} / \mathrm{C}_{\mathrm{o}}$, for $\mathrm{SeO}_{3}{ }^{2-}$ or $\mathrm{SeO}_{4}{ }^{2-}$ versus pore volumes eluted. Both equilibrium and non-equilibrium (two site/two region) models were applied to analyze the experimental column breakthrough data [29]. The equilibrium model described in dimensionless terms is

$$
R \frac{\partial C}{\partial T}=\frac{1}{P} \frac{\partial^{2} C}{\partial Z^{2}}-\frac{\partial C}{\partial Z}
$$

(3a)where

$$
T=\frac{v t}{L}, \quad Z=\frac{x}{L}, \quad C=\frac{c}{c_{O}}, \quad P=\frac{v L}{D}, \quad R=1+\frac{\rho B K d}{\theta}(3 \mathrm{~b})
$$

and $\mathrm{T}=$ dimensionless time equal to pore volume; $\mathrm{t}=$ time $(\mathrm{T})$; $\mathrm{L}=$ column length $(\mathrm{L})$; $\mathrm{v}=$ linear pore water velocity $\left(\mathrm{LT}^{-1}\right)$; $\mathrm{Z}=$ dimensionless distance; $\mathrm{x}=$ distance from the input $(\mathrm{L}) ; \mathrm{C}=$ relative concentration between initial $\left(c_{o}\right)$ and effluent (c) concentrations $\left(\mathrm{ML}^{-3}\right)$; $\mathrm{P}=$ Peclet number [-]; $\mathrm{D}=$ hydrodynamic dispersion coefficient $\left(\mathrm{L}^{2} \mathrm{~T}^{-1}\right) ; \mathrm{R}[-]=$ retardation factor determined by the equation containing bulk density $\left(\rho_{\mathrm{b}}\right)\left(\mathrm{ML}^{-3}\right)$, porosity $(\Theta)\left(\mathrm{L}^{3} \mathrm{~L}^{-3}\right)$, and distribution coefficient $\left(\mathrm{K}_{\mathrm{d}}\right)\left(\mathrm{M}^{-1} \mathrm{~L}^{3}\right)$. The non-equilibrium model is described by the following equations with dimensionless terms:

$$
\begin{aligned}
& \beta R \frac{\partial C_{1}}{\partial T}+(1-\beta) R \frac{\partial C_{2}}{\partial T}=\frac{1}{P} \frac{\partial^{2} C_{1}}{\partial Z^{2}}-\frac{\partial C_{1}}{\partial Z} \\
& (1-\beta) R \frac{\partial C_{2}}{\partial T}=\omega\left(C_{1}-C_{2}\right) \\
& T=\frac{V t}{L}, \quad Z=\frac{x}{L}, \quad C_{1}=\frac{c_{m}}{c_{O}}, \quad C_{2}=\frac{c_{i m}}{c_{O}}(4 \mathrm{c}) \\
& P=\frac{V m L}{D_{m}}=\frac{V L}{D}, \quad V m=\frac{q}{\theta_{m}}, \quad \omega=\frac{\alpha L}{v_{m} \theta_{m}}, \quad \beta=\frac{\theta_{m}+f \rho b K d}{\theta+\rho b K d}(4 \mathrm{~d})
\end{aligned}
$$

where $\beta=$ dimensionless mobile fraction with mobile water fraction (f); $\mathrm{Cl}=$ solute concentration in mobile water $\left(\mathrm{ML}^{-3}\right) ; \mathrm{C}_{2}=$ solute concentration in immobile water $\left(\mathrm{ML}^{-3}\right) ; \omega=$ dimensionless mass transfer coefficient between mobile and immobile water regions; $\alpha=$ mass transfer coefficient $\left[\mathrm{T}^{-1}\right] ; \mathrm{q}=$ volumetric flow velocity $\left[\mathrm{LT}^{-1}\right]$. The column parameters are summarized below in Table 4 .

\begin{tabular}{|l|l|l|l|l|l|l|l|}
\hline $\begin{array}{l}\text { Colum } \\
\text { ns }\end{array}$ & $\begin{array}{l}\text { Porosi } \\
\text { ty [-] }\end{array}$ & $\begin{array}{l}\text { Porewat } \\
\text { er } \\
\text { velocity } \\
(\mathbf{c m} / \\
\text { day) }\end{array}$ & $\begin{array}{l}\text { Pore } \\
\text { volum } \\
\mathbf{e} \\
\left(\mathbf{c m}^{3}\right)\end{array}$ & $\begin{array}{l}\text { Bulk } \\
\text { densit } \\
\mathbf{y} \\
\mathbf{( g /} / \\
\left.\mathbf{c m}^{3}\right)\end{array}$ & $\begin{array}{l}\mathbf{D}^{1}\left(\mathbf{c m}^{2} /\right. \\
\text { day) }\end{array}$ & $\begin{array}{l}\text { Retardati } \\
\text { on factor } \\
\left(\mathbf{R}_{\mathrm{f}}\right)\end{array}$ & $\begin{array}{l}\mathbf{K d} \\
(\mathbf{m L} / \mathrm{g})\end{array}$ \\
\hline $\begin{array}{l}\text { Selenit } \\
\text { e }\end{array}$ & 0.29 & 8.17 & 15.3 & 1.59 & 7.09 & 3.10 & 0.38 \\
\hline $\begin{array}{l}\text { Selenat } \\
\text { e }\end{array}$ & 0.29 & 8.17 & 15.7 & 1.68 & 5.56 & 1.20 & 0.034 \\
\hline
\end{tabular}

Table 4: Transport parameters of selenite and selenate columns. 1 Hydrodynamic dispersion coefficient.

\section{Results and Discussion}

\section{Batch selenium adsorption}

Adsorption of Se on quartz under varying $\mathrm{pHs}$ (2-11) and ionic strengths ( $\mathrm{I}=0.01 \mathrm{M}$ to $1.0 \mathrm{M} \mathrm{NaNO}_{3}$ ) resulted in negligible adsorption of $\mathrm{SeO}_{4}{ }^{2-}$ regardless of $\mathrm{pH}$ and ionic strength conditions (Figure 2).

Even at low $\mathrm{pH}(<4)$ and ionic strength $\left.(\mathrm{I}=0.01 \quad \mathrm{M} \mathrm{NaNO})_{3}\right)$ conditions, no adsorption of $\mathrm{SeO}_{4}{ }^{2-}$ was found on the quartz surfaces. Selenite $\left(\mathrm{SeO}_{3}{ }^{2-}\right)$ showed a minor amount of adsorption $(<10 \%)$ onto the quartz at $\mathrm{pH}$ values less than 5 and only at low ionic strengths $\left(\mathrm{I}=0.01 \mathrm{M}\right.$ and $\left.0.1 \mathrm{M} \mathrm{NaNO}_{3}\right)$. Because the adsorption was so small $(<10 \%)$ it is difficult to see a trend in the data. The only thing we can conclude from the data trend is that $\mathrm{SeO}_{3}{ }^{2-}$ showed a slight high adsorption at certain $\mathrm{pH}$, especially at low $\mathrm{pH}$ even at high ionic strength condition. An increase in $\mathrm{SeO}_{3}{ }^{2-}$ adsorption at low $\mathrm{pH}$ is due to the low point of zero charge (PZC) of quartz (pHPZC 2.82) [30]. 
At low $\mathrm{pH}$ conditions the surface adsorption sites for quartz are positively charged through protonation of surface charge, which is consistent with the fact that oxide and hydroxide surfaces are positively charged at lower $\mathrm{pH}$ and negatively charged at higher $\mathrm{pH}$ than that of the PZC value of the adsorbent [31]. Based on the increased $\mathrm{SeO}_{3}{ }^{2-}$ adsorption to quartz at low ionic strengths $(\mathrm{I}=0.01$ and $0.1 \mathrm{M}$ ) and low $\mathrm{pH}$ conditions, (although minor), $\mathrm{SeO}_{3}{ }^{2-}$ is considered to have slightly higher adsorption affinity to quartz than $\mathrm{SeO}_{4}{ }^{2-}$ which exhibits no detectable adsorption onto quartz at all conditions studied.

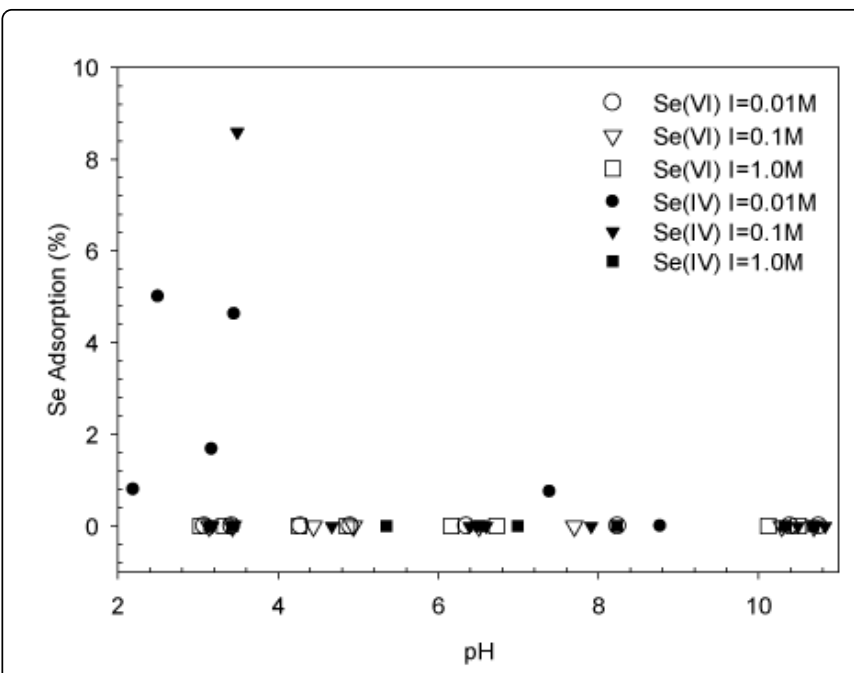

Figure 2: Adsorption of Se (\%) versus $\mathrm{pH}$ with varying ionic strengths $\left(\mathrm{I}=0.01 \mathrm{M}, 0.1\right.$ and $\left.1.0 \mathrm{M} \mathrm{NaNO}_{3}\right)$ on quartz.

Adsorption of $\mathrm{SeO}_{3}{ }^{2-}$ on synthetic ferrihydrite at varying $\mathrm{pH}$ (4-8) and at fixed ionic strength $\left(\mathrm{I}=0.1 \mathrm{M} \mathrm{NaNO}_{3}\right)$ resulted in nearly $100 \%$ adsorption (98.4\% to $99.9 \%$ ) (Figure 3). However, $\mathrm{SeO}_{4}{ }^{2-}$ displayed adsorption ranging from 6 to $82 \%$, with decreasing adsorption as $\mathrm{pH}$ increased, with higher percentages of uptake at the lower $\mathrm{pH}$ ranges $(<7)$. The high adsorption of $\mathrm{SeO}_{4}{ }^{2-}$ at $\mathrm{pH}<7$ was attributed to the higher PZC of iron oxide $\left(\mathrm{pH}_{\mathrm{PZC}}=8.5\right.$ to 8.8$)$ compared to that of quartz $\left(\mathrm{pH}_{\mathrm{PZC}} \sim 2.82\right)$ [31]. There were more discernable adsorption differences between $\mathrm{SeO}_{3}{ }^{2-}$ and $\mathrm{SeO}_{4}{ }^{2-}$ as the $\mathrm{pH}$ changed, indicating that $\mathrm{SeO}_{3}{ }^{2-}$ has a higher adsorption affinity to $\mathrm{Fe}$ oxide similar to the Se adsorption results on quartz. In addition, the elevated adsorption of $\mathrm{SeO}_{3}{ }^{2-}$ compared to $\mathrm{SeO}_{4}{ }^{2-}$ onto the $\mathrm{Fe}$ oxide at all $\mathrm{pH}$ conditions also suggests a higher adsorption affinity of $\mathrm{SeO}_{3}{ }^{2-}$ which agrees with the results of Se adsorption on the quartz.

Adsorption results for Se onto aluminum oxide under different ionic strengths ( $\mathrm{I}=0.01$ to $1.0 \mathrm{M} \mathrm{NaNO}_{3}$ ) and varying pHs (4 - 10) are shown in Figure 4. Selenite adsorption on aluminum oxide was greater than $96 \%$ at $\mathrm{pH}<8.5$ with no discernable effect from varying ionic strength ( $\mathrm{I}=0.01$ and $1.0 \mathrm{M} \mathrm{NaNO}_{3}$ ). High adsorption affinity of $\mathrm{SeO}_{3}$ 2- on alumina oxide at low $\mathrm{pHs}$ was attributed to the high surface area $\left(110 \mathrm{~m}^{2} \mathrm{~g}^{-1}\right)$ and $\mathrm{PZC}$ of alumina oxide $\left(\mathrm{pH}_{\mathrm{PZC}}=8.5\right)$ [25], resulting in positive surface charges due to protonation of alumina oxide surface at lower $\mathrm{pH}(\mathrm{pH}<8.5)$. Decreasing adsorption of $\mathrm{SeO}_{3}{ }^{2-}$ was found as $\mathrm{pH}$ increased, especially at higher $\mathrm{pHs}(>8.0)$ because of the negatively charged alumina surfaces at high pHs. In contrast, $\mathrm{SeO}_{4}{ }^{2-}$ adsorption onto aluminum oxide was largely affected by changes in ionic strength from $0.01 \mathrm{M}$ to $1.0 \mathrm{M} \mathrm{NaNO}_{3}$. Selenate adsorption decreased as both ionic strength and $\mathrm{pH}$ increased (Figure 3).

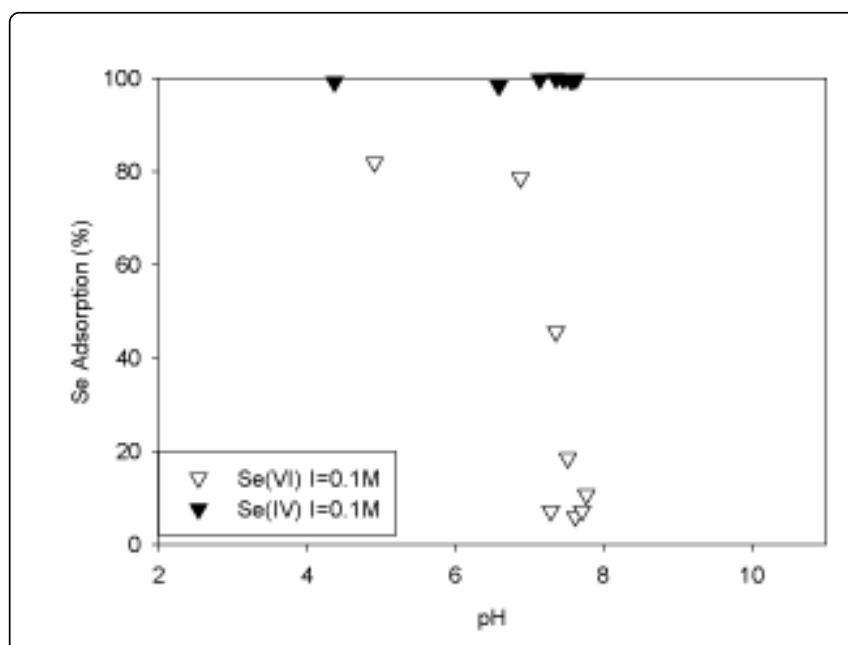

Figure 3: Adsorption of $\mathrm{Se}(\%)$ versus $\mathrm{pH}$ with ionic strengths $\mathrm{I}=0.1 \mathrm{M} \mathrm{NaNO}_{3}$ on ferrihydrite.

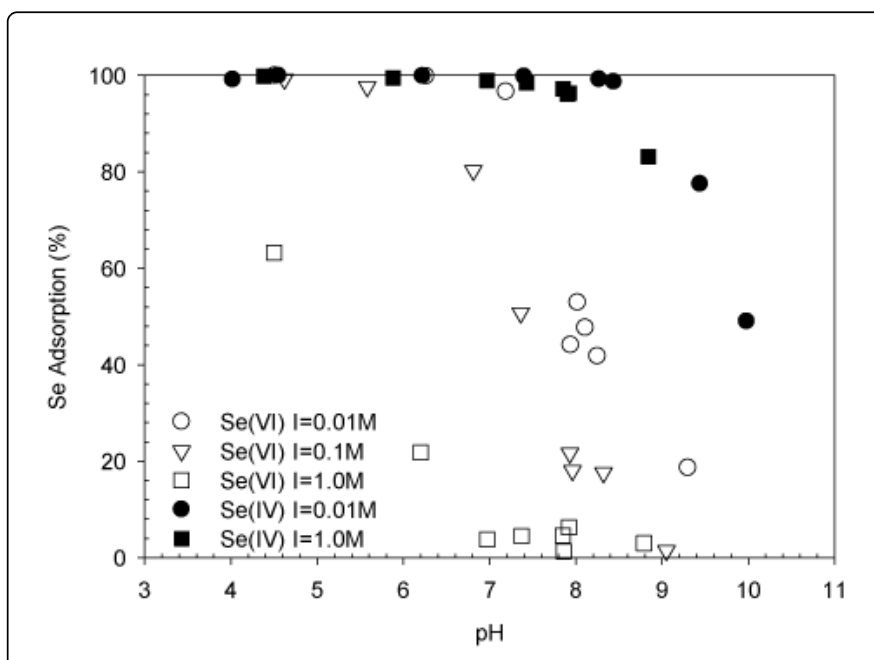

Figure 4: Adsorption of Se (\%) versus $\mathrm{pH}$ with varying ionic strengths $\left(\mathrm{I}=0.01 \mathrm{M}, 0.1 \mathrm{M}\right.$ and $\left.1.0 \mathrm{M} \mathrm{NaNO}_{3}\right)$ on aluminum oxide.

As ionic strength increased from $\mathrm{I}=0.01 \mathrm{M}$ to $1.0 \mathrm{M} \mathrm{NaNO}_{3}$, there is an increase in concentration of anions (e.g., $\mathrm{NO}_{3}{ }^{-}$) from the background electrolyte, which competes with $\mathrm{SeO}_{4}{ }^{2-}$ for available adsorption sites. The ionic-strength dependence of $\mathrm{SeO}_{4} 2$ - adsorption suggests an outer-sphere surface complex, while the $\mathrm{SeO}_{3}{ }^{2-}$ adsorption suggests formation of an inner-sphere surface complex because of the independent adsorption behavior of $\mathrm{SeO}_{3}{ }^{2-}$ with respect to varying background ionic strengths. Due to a weaker electrostatic bond, outersphere complexes are less stable and considered to be relatively weakly binding. A strong dependence on ionic strength is typically found in species that form outer-sphere surface complexes [31]. Conversely, the ionic strength independence of $\mathrm{SeO}_{3}{ }^{2-}$ adsorption suggests a stronger covalent bond indicative of an inner-sphere complex and direct binding of $\mathrm{SeO}_{3}{ }^{2-}$ to the solid surface without the presence of coadsorbed water molecules [31]. Based on the general comparison of 
$\mathrm{SeO}_{3}{ }^{2-}$ and $\mathrm{SeO}_{4}{ }^{2-}$ adsorption on three different single minerals, $\mathrm{SeO}_{3}{ }^{2-}$ showed a much higher adsorption affinity on all the adsorbents, suggesting a higher adsorption affinity due to a stronger bonded inner-sphere surface complex.

The adsorption of Se on the Hanford sediment was also measured using Hanford natural groundwater (Table 3). The results of Se adsorption ( $\mathrm{K}_{\mathrm{d}}$ values) were between 0 and $3 \mathrm{~mL} \mathrm{~g}^{-1}$ for $\mathrm{SeO}_{4}{ }^{2-}$, and slightly higher values for $\mathrm{SeO}_{3}{ }^{2-}$ ranging from 0 to $22 \mathrm{mLg}^{-1}$, respectively (Figures 5 and 6). A decrease in the adsorption $\mathrm{K}_{\mathrm{ds}}$ for both $\mathrm{SeO}_{3}{ }^{2-}$ and $\mathrm{SeO}_{4}{ }^{2-}$ as the initial $\mathrm{Se}$ concentration increased signifies the potential for nonlinear adsorption behavior for Se onto Hanford sediments. At fixed solid to solution ratio and initial Se concentration conditions, $\mathrm{SeO}_{3}{ }^{2-} \mathrm{K}_{\mathrm{ds}}$ were higher than those found for $\mathrm{SeO}_{4}{ }^{2-}$, which agrees with the previous $\mathrm{Se}$ adsorption experiments conducted on pure single minerals.

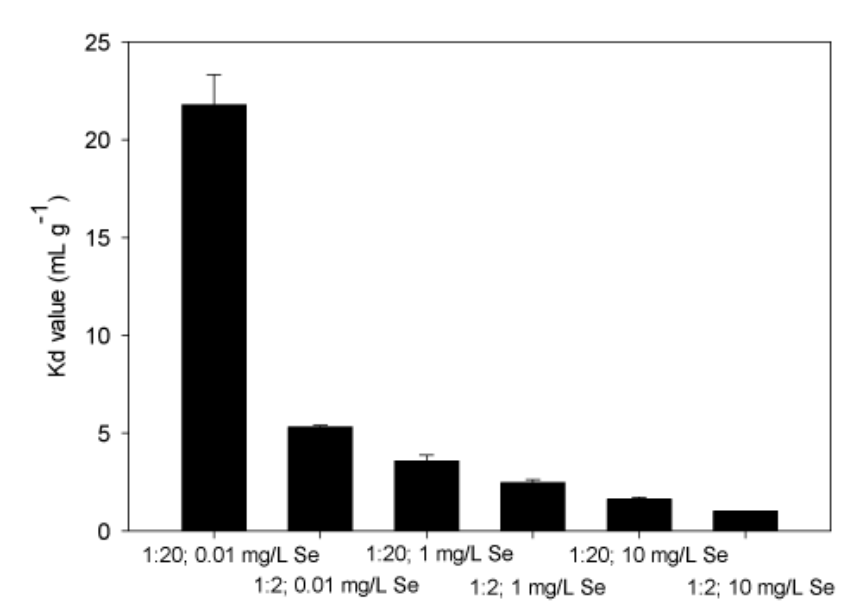

Figure 5: Selenite batch $\mathrm{K}_{\mathrm{d}}$ results $\left(\mathrm{mL} \mathrm{g}^{-1}\right)$ with varying solid to solution ratios $(1: 20,1: 2)$ and Se concentrations $(0.01,1$ and $10 \mathrm{mg}$ $\left.\mathrm{L}^{-1}\right)$.

\section{Selenium transport in column experiments}

The BTCs for the nonreactive $\mathrm{Br}$ tracer and $\mathrm{SeO}_{4}{ }^{2-}$ in groundwater through Hanford sediment is shown in Figure 7. The Br transport was not retarded by the Hanford sediment, resulting in a retardation value $\left(\mathrm{R}_{\mathrm{f}}\right)$ of 1.0. The hydrodynamic dispersion coefficient for the packed columns was obtained from the CXTFIT curve fit on the Br BTC and fixed in the equilibrium model that was applied to the $\mathrm{SeO}_{4}{ }^{2-}$ BTC. The transport of $\mathrm{SeO}_{4}{ }^{2-}$ was slightly retarded when compared to the $\mathrm{Br}$ $\mathrm{BTC}$ and reached a relative concentration $\left(\mathrm{C} / \mathrm{C}_{\mathrm{o}}\right)$ of 1.0 after only 2.0 pore volumes, resulting in a $\mathrm{R}_{\mathrm{f}}$ value of 1.2 (Table 4). The comparable retardation of $\mathrm{Br} \quad\left(\mathrm{R}_{\mathrm{f}}=1.0\right)$ and $\mathrm{SeO}_{4}{ }^{2-} \quad\left(\mathrm{R}_{\mathrm{f}}=1.2\right)$ indicates weak adsorption affinity of $\mathrm{SeO}_{4}{ }^{2-}$ on the Hanford sediment and was consistent with the previous batch adsorption results. Minor tailing was noticed for the $\mathrm{SeO}_{4}{ }^{2-}$ transport at pore volume $>15$ (Figure 7) and showed an asymmetric $\mathrm{BTC}$ for $\mathrm{SeO}_{4}{ }^{2-}$, which suggests the presence of immobile regions resulting in physical non-equilibrium. However, the non-equilibrium model did not improve the fit results when compared to the equilibrium model, indicating that the non-equilibrium conditions were not significant for $\mathrm{SeO}_{4}{ }^{2-}$ transport in the column.

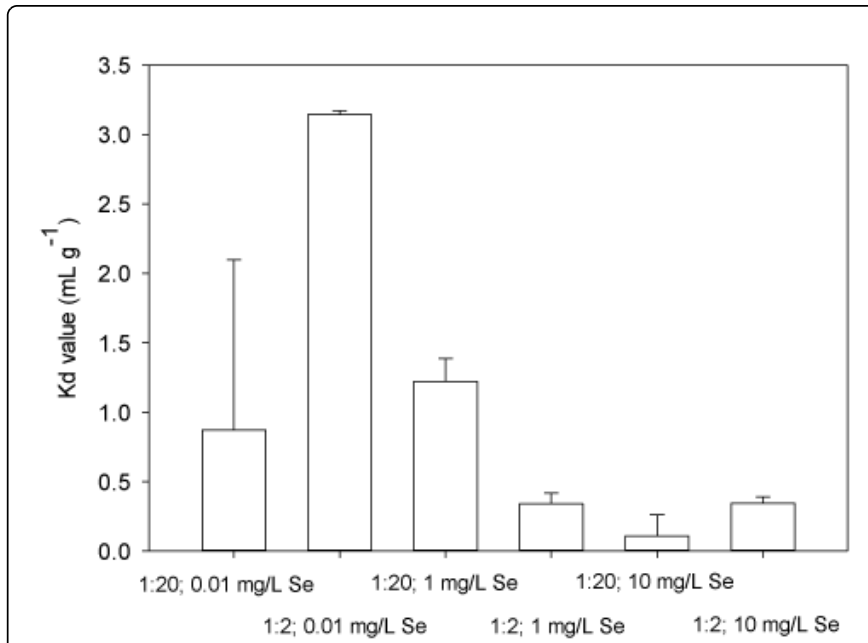

Figure 6: Selenate batch $\mathrm{K}_{\mathrm{d}}$ results $\left(\mathrm{mL} \mathrm{g}^{-1}\right)$ with varying solid to solution ratios (1:20, 1:2) and Se concentrations (0.01, 1 and $10 \mathrm{mg}$ $\left.\mathrm{L}^{-1}\right)$.

The BTCs for $\mathrm{Br}$ and $\mathrm{SeO}_{3}{ }^{2-}$ with the equilibrium model fit are shown in Figure 8 and Table 4. Because the BTCs for $\mathrm{Br}$ and $\mathrm{SeO}_{3}{ }^{2-}$ are fairly symmetric, an equilibrium model was used for both the $\mathrm{Br}$ and $\mathrm{SeO}_{3}{ }^{2-}$ BTCs. The BTC for $\mathrm{SeO}_{3}{ }^{2-}$ showed more retardation (with respect to $\mathrm{Br}$ transport) and did not reach complete breakthrough until approximately 6.5 pore volumes (Figure 8 ). The CXTFIT model fit to the $\mathrm{SeO}_{3}{ }^{2-}$ column experiment resulted in an $\mathrm{R}_{\mathrm{f}}$ value of 3.1. The $\mathrm{SeO}_{3}{ }^{2-}$ column experiment displayed a higher adsorption resulting in more retarded transport of $\mathrm{SeO}_{3}{ }^{2-}$ compared to the low adsorption of $\mathrm{SeO}_{4}{ }^{2-}$ which displayed negligible retardation.

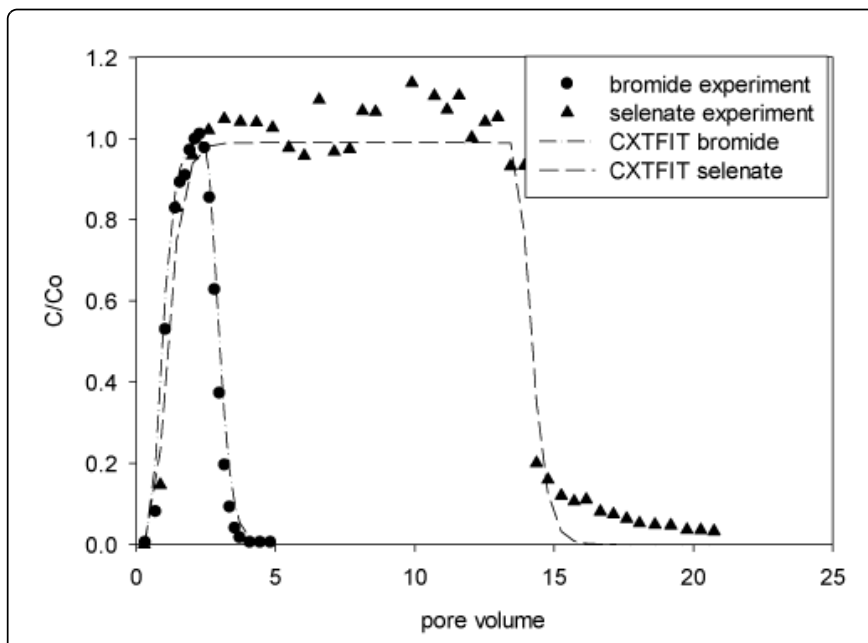

Figure 7: Selenate column experiment and CXTFIT equilibrium model results. 


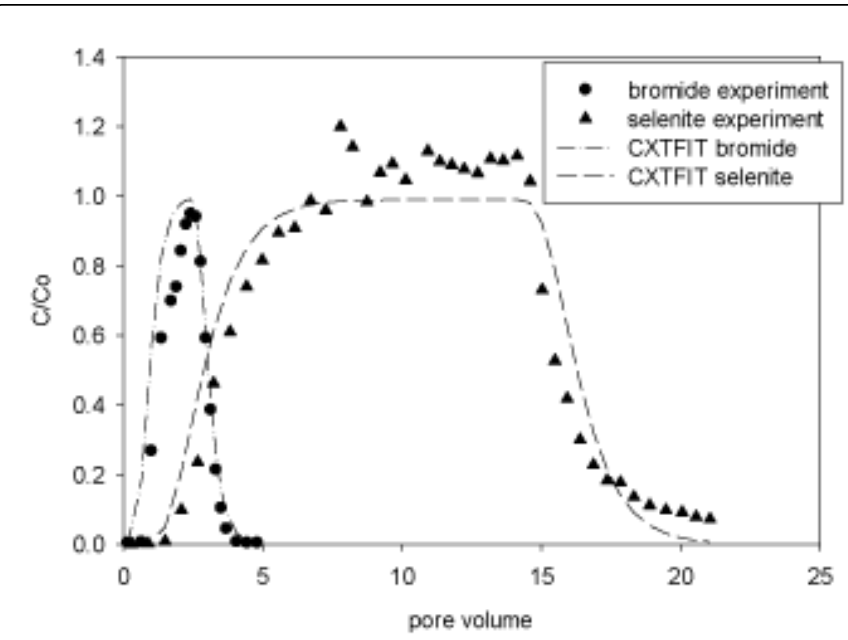

Figure 8: Selenite column experiment and CXTFIT equilibrium model results.

The calculated $\mathrm{K}_{\mathrm{ds}}$ based on the retardation values obtained from the column experiments (Table 4) showed the same trend for adsorption affinity between $\mathrm{SeO}_{3}{ }^{2-}$ and $\mathrm{SeO}_{4}{ }^{2-}$ as observed in the batch adsorption experiments. The smaller calculated $\mathrm{K}_{\mathrm{d}}$ values for selenitie and selenate from the column experiments compared to those obtained from the batch experiments are considered to be a result of the different solid to solution ratios and contact times between the two sets of experiments. The batch and column experiments showed the same trends for $\mathrm{SeO}_{3}{ }^{2-}$ and $\mathrm{SeO}_{4}{ }^{2-}$ adsorption, indicating different adsorption affinities due to different adsorption mechanisms forming inter- vs. outer-sphere complexes for $\mathrm{SeO}_{3}{ }^{2-}$ and $\mathrm{SeO}_{4}{ }^{2-}$, respectively. These different adsorption mechanisms should be considered in fate and transport predictions and future performance assessment activities should utilize the different mobility attributes for the Se species, $\mathrm{SeO}_{3}{ }^{2-}$ and $\mathrm{SeO}_{4}{ }^{2-}$, at the Hanford Site.

\section{Conclusions}

The batch adsorption experiments on quartz, aluminum oxide and iron oxide (ferrihydrite) resulted in a higher adsorption affinity for $\mathrm{SeO}_{3}{ }^{2-}$ than $\mathrm{SeO}_{4}{ }^{2-}$ with higher adsorption at the lower $\mathrm{pHs}$. Particularly important are the batch adsorption results on the Fe and $\mathrm{Al}$ oxides, which showed a higher adsorption capacity for Se, especially at circum neutral $\mathrm{pH}$ conditions. The $\mathrm{SeO}_{3}{ }^{2-}$ batch adsorption results showed an ionic strength independence, while the $\mathrm{SeO}_{4}{ }^{2-}$ adsorption showed ionic strength dependence (i.e., adsorption increased as the ionic strength decreased). Ionic strength dependence or independence in adsorption results indicates that $\mathrm{SeO}_{4}{ }^{2-}$ displays an outer-sphere adsorption surface complex and $\mathrm{SeO}_{3}{ }^{2-}$ forms a stronger bonded inner-sphere adsorption surface complex. The batch adsorption experiments on the Hanford sediment with natural Hanford groundwater at $\mathrm{pH}$ between 7.0 to 8.5 resulted in a maximum $\mathrm{K}_{\mathrm{d}}$ value of 21.8 and $3.14 \mathrm{mg} \mathrm{L}^{-1}$ for $\mathrm{SeO}_{3}{ }^{2-}$ and $\mathrm{SeO}_{4}{ }^{2-}$, respectively. In agreement with the batch adsorption experiments, the column experiments yielded negligible adsorption of $\mathrm{SeO}_{4}{ }^{2-}$ with an $\mathrm{R}_{\mathrm{f}}$ of 1.2, while $\mathrm{SeO}_{3}{ }^{2-}$ showed higher adsorption with a $\mathrm{R}_{\mathrm{f}}$ of 3.1. All experimental results at the same background conditions showed higher adsorption for $\mathrm{SeO}_{3}{ }^{2-}$ than $\mathrm{SeO}_{4}{ }^{2-}$ concluding that $\mathrm{SeO}_{4}{ }^{2-}$, the oxidized form of $\mathrm{Se}$, will be more mobile than $\mathrm{SeO}_{3}{ }^{2-}$ in the environment.

The pure single mineral experiments resulted in minor amounts of Se adsorption on the quartz and much higher percentages of adsorption on aluminum and iron oxides. Hanford soils are dominated by quartz with lesser amounts of aluminum- and ironbearing minerals. The composition of Hanford sediments leads to the conclusion that there will likely not be a high percentage of Se adsorption on Hanford sediment, particularly at high $\mathrm{pH}$ conditions similar to natural Hanford soil (7.5-8.5).

\section{Acknowledgments}

This study was conducted in support of the ILAW project with funding from the Office of River Protection (DOE) managed by CH2M-HILL Hanford Company. Eric Clayton and Steven Baum (PNNL) are also acknowledged for providing analytical support. The authors would like to thank Jeff Serne, Chris Brown and Dawn Wellman (PNNL) for their comments and suggestions to improve this manuscript. PNNL is operated by Battelle for the U.S. Department of Energy under contracts DE-AC006-76RLO 1830. A portion of this research was carried out at the POSTECH supported by WCU (World Class University) and BK21+ programs at the Division of Advanced Nuclear Engineering (DANE) in POSTECH through the National Research Foundation of Korea funded by the Ministry of Education, Science and Technology (R31-30005).

\section{References}

1. EPA (2012) National Primary Drinking Water Regulations-Inorganic Chemicals. US Environmental Protection Agency.

2. Engberg RA, Westcot DW, Delamore M, Holz DD (1998) Federal and State Perspectives on Regulation and Remediation of Irrigation-Induced Selenium Problems.

3. Mayland HF (1994) Selenium in Plant and Animal Nutrition. In: Frankenberger JWT, Sally Benson (edn) Selenium in the Environment Marcel Dekker Inc New York.

4. Lockheed Martin (2002) Chart of the Nuclides (16edn).

5. Mann FM, Puigh RJ, Rittmann PD, Kline NW, Voogd JA, et al. (1998) Hanford Immobilized Low-Activity Tank Waste Performance Assessment. US Department of Energy Richland WA.

6. Kaplan DI, Serne RJ (2000) Geochemical Data Package for the Hanford Immobilized Low-Activity Tank Waste Performance Assessment (ILAW PA). Pacific Northwest National Laboratory.

7. McGrail B, Bacon D, Serne R, Pierce E (2003) A Strategy to Assess Performance of Selected Low-Activity Waste Forms in an Integrated Disposal Facility. Pacific Northwest National Laboratory.

8. Sposito G (1982) On the Surface Complexation Model of the OxideAqueous Solution Interface. J Colloid Interface Sci 91: 329-340.

9. Sposito G (1986) Distinguishing Adsorption from Surface Precipitation. Geochem Process Miner Surf 323: 217-228.

10. Stumm W (1992) Chemistry of the Solid-Water Interface: Processes at the Mineral-Water and Particle-Water Interface in Natural Systems. John Wiley and Sons Inc. Canada.

11. Breynaert E, Scheinost AC, Dom D, Rossberg A, Vancluysen J, et al. (2010) Reduction of Se(IV) in boom clay: XAS solid phase speciation. Environ Sci Technol 44: 6649-6655.

12. Balistrieri LS, Chao TT (1987) Selenium Adsorption by Goethite. Soil Sci Soc Am J 51: 1145-1151.

13. Boyle-Wight EJ, Katz LE, Hayes KF (2002a) Macroscopic Studies of the Effects of Selenate and Selenite on Cobalt Sorption to Al2O3. Environ Sci Technol 36: 1212-1218. 
Citation: Michelle MV Snyder and Wooyong Um (2014) Adsorption Mechanisms and Transport Behavior between Selenate and Selenite on Different Sorbents. Int J Waste Resources 4: 144. doi:10.4172/2252-5211.1000144

Page 8 of 8

14. Boyle-Wight EJ, Katz LE, Hayes KF (2002b) Spectroscopic Studies of the Effects of Selenate and Selenite on Cobalt Sorption to Al2O3. Environ Sci Technol 36: 1219-1225.

15. Duc M, Lefèvre G, Fédoroff M (2006) Sorption of selenite ions on hematite. J Colloid Interface Sci 298: 556-563.

16. Zhang P, Sparks DL (1990) Kinetics of Selenate and Selenite Adsorption/ Desorption at the Goethite/Water Interface. Environ Sci Technol 24: 1848-1856.

17. Gonzalez CM, Hernandez J, Parsons JG, Gardea-Torresdey JL (2010) A Study of the Removal of Selenite and Selenate from Aqueous Solutions Using a Magnetic Iron/Manganese Oxide Nanomaterial and ICP-MS. Microchemical Journal 96: 324-329.

18. Zonkhoeva EL, Sanzhanova SS (2011) Infrared Spectroscopy Study of the Sorption of Selenium(IV) on Natural Zeolites. Russian Journal of Physical Chemistry 85: 1233-1236.

19. Yoon IH, Kim KW, Bang S, Kim MG (2011) Reduction and Adsorption Mechanisms of Selenate by Zero-valent Iron and Related Iron Corrosion. Applied Catalysis B: Environmental 104: 185-192.

20. Sharmasarkar S, Vance GF (2002) Selenite-Selenate Sorption in Surface Coal Mine Environment Adv Environ Res 7: 87-95.

21. Horton DG, Schaef HT, Serne RJ, Brown CF, Valenta MM (2003) Geochemistry of Samples From Borehole C3177 (299-E24-21). Pacific Northwest National Laboratory.

22. Reidel SP (2002) Geologic Data Package for 2005 Integrated Disposal Facility Waste Performance Assessment. Pacific Northwest National Environment.

23. Bickmore BR, Nagy KL, Young JS, Drexler JW (2001) Nitrate-cancrinite precipitation on quartz sand in simulated Hanford tank solutions. Environ Sci Technol 35: 4481-4486.
24. Papelis C, Roberts PV, Leckie JO (1995) Modeling the rate of cadmium and selenite adsorption on micro- and mesoporous transition aluminas. Environ Sci Technol 29: 1099-1108.

25. Papelis C (1992) Cadmium and Selenite Adsorption on Porous Aluminum Oxides: Equilibrium Rate of Uptake and Spectroscopic Studies Department of Civil Engineering and the Committe on Graduate Studies Stanford University, Stanford.

26. Schwertmann U, Cornell RM (2000) Iron Oxides in the Laboratory: Preparation and Characterization. Weinheim: Wiley-VCH.

27. EPA (1999) Understanding Variation in Partition Coefficient, Kd, Values Volume I: The Kd Model Methods of Measurement and Application of Chemical Codes. Office of Radiation and Indoor Air and Office of Environmental Restoration.

28. Parker JC, Vangenuchten MT (1984) Determining transport parameters from laboratory and field tracer experiments. Virginia Agricultural Experiment Station Bulletin 1-96.

29. Toride N, Leij FJ, Genuchten MT (1999) The CXTFIT Code for Estimating Transport Parameters from Laboratory or Field Tracer Experiments. US Salinity Laboratory. US Department of Agriculture Riverside California.

30. Goyne KW, Zimmerman AR, Newalkar BL, Kormarneni S, Brantley SL, et al., (2002) Surface Charge of Variable Porosity Al2O3(s) and SiO2(s) Adsorbents. Journal of Porous Materials 9: 243-256.

31. Langmuir D (1997) Aqueous Environmental Geochemistry. PrenticeHall Inc. Upper Saddle River New Jersey. 